\title{
Using Social Network Analysis to Monitor and Assess the Effectiveness of Knowledge Brokers at Connecting Scientists and Decision-Makers: An Australian case study
}

C. Cvitanovic, ${ }^{1 *}$ R. Cunningham, ${ }^{2,6}$ A-M. Dowd, ${ }^{3}$ S.M. Howden ${ }^{4}$ and E.I. van Putten ${ }^{1,5}$ ${ }^{7}$ Centre for Marine Socioecology, University of Tasmania, Battery Point, Tasmania, Australia ${ }^{2}$ Tyndall Centre for Climate Change, University of Manchester, Department of Mechanical, Aerospace and Civil Engineering, UK

${ }^{3}$ Commonwealth Scientific and Industrial Research Organisation (CSIRO), Kenmore, QLD, Australia ${ }^{4}$ Climate Change Institute, Australian National University, Canberra, ACT, Australia ${ }^{5}$ CSIRO Oceans and Atmosphere, Hobart, Tasmania, Australia ${ }^{6}$ Institute for Sustainable Futures, University of Technology Sydney, City Campus, Broadway, NSW 2009, Australia

\begin{abstract}
Despite growing rhetoric regarding the potential benefits of using knowledge brokers in relation to environmental challenges and decision-making processes, the evidence in support of such claims is mostly anecdotal. This is, in part, due to the lack of established methods to evaluate the effectiveness and efficiency of knowledge brokers. To address this gap we assess the utility of social network analysis (SNA) to evaluate the effectiveness of knowledge brokers in connecting scientists and decision-makers. Specifically, using a case-study approach, we undertake longitudinal SNA over a 12-month period to evaluate the extent to which the knowledge broker developed networks between producers and users of knowledge across different organizations. We also undertook a qualitative survey of scientists $(n=29)$ who worked in the same organization as the knowledge broker to understand the extent to which the knowledge broker increased the impact of scientific research for decision-making purposes. Results show that the knowledge broker developed an extensive stakeholder network of 192 individuals spanning over 30 organizations. The results of the SNA found that over time this network increased in density and became more cohesive, both key elements underpinning successful knowledge exchange. Furthermore, the qualitative survey found that the knowledge broker also had a positive impact in other ways, including helping researchers understand the operating environments within decision-making agencies and the best approaches for engaging with specific decision-makers. Thus, this study demonstrates the value of SNA for evaluating knowledge brokers and provides empirical support for the use of knowledge brokers in the environmental sector. Copyright @ 2017 John Wiley \& Sons, Ltd and ERP Environment
\end{abstract}

Keywords: social network analysis; knowledge exchange; knowledge transfer; science-policy; governance; evidence-based decision-making "Correspondence to: C. Cvitanovic, Centre for Marine Socioecology, University of Tasmania, Battery Point, Tasmania, Australia. E-mail: christopher.cvitanovic@utas.edu.au 


\section{Introduction}

HE SUSTAINABLE MANACEMENT OF ENVIRONMENTAL RESOURCES REMAINS A SICNIFICANT CHALLENGE, (BERKES ET AL., 2003). IN response, a growing body of literature advocates for the implementation of adaptive governance structures promoting collaborative, flexible and learning based approaches to management (Folke et al., 2003; Nelson et al., 2008). A critical factor underpinning the success of adaptive governance arrangements is the generation and sharing of new information, as well as the capacity of management organizations to learn from new information (Armitage et al., 2008). However, despite a significant increase in the production of scientific knowledge, an implementation gap remains (Ormerod et al., 2002; Berrang-Ford et al., 20II). Rather, evidence suggests that decision-makers often rely on experiential knowledge when developing and implementing conservation and management actions in isolation from evidence-based science (Pullin et al., 2004; Cvitanovic et al., 2014a; Addison et al., 2015), limiting the potential success of management actions. Accordingly, improving knowledge exchange among scientists and decision-makers to support adaptive governance structures is an emergent priority for the environmental sector (Cornell et al., 20I3; Meadow et al., 20I5).

While there are a number of ways in which knowledge exchange can be improved among scientists and decisionmakers (e.g. boundary organizations, knowledge co-production, etc. - reviewed by Cvitanovic et al., 20I5b), in recent times a growing body of literature has advocated for the use of knowledge brokers to enhance the likelihood of evidenced-based decision-making (e.g. Cvitanovic et al., 2013; Reed et al., 20I4; Hering, 2015; Lacey et al., 2015). While knowledge brokers are conceptualized and operationalized differently in various sectors and settings (Hoppe, 2009), the defining feature of such a role is to develop relationships and networks with, among and between producers and users of knowledge to facilitate the exchange of knowledge throughout this network and build capacity for evidence-based decision-making (Bornbaun et al., 20I5). To do so, knowledge brokers are required to build and sustain productive working relationships with a range of stakeholders, be they individuals or organizations, to understand their existing knowledge base and capacity for evidence-based decision-making and to subsequently help build these (Lomas, I997). Underpinning this is the extent to which knowledge brokers are perceived by their stakeholders as relevant, legitimate and credible (Cash et al., 2003; Cash and Buizer, 2005; Reinecke, 20I5), which requires knowledge brokers to have not only an in-depth understanding of the science that they are to communicate, but also a strong understanding of the stakeholders with whom they engage, their operational environment and the most appropriate avenues to influence the research and how it is conducted (Michaels, 2009; Stocklmayer, 2013; Saarela and Söderman, 2015). In turn, knowledge brokers must also have the ability to interpret and frame stakeholder needs and then communicate these to the research community. Finally, for knowledge brokers to act efficiently it is widely believed that they must possess superior interpersonal skills, communication skills and motivational skills (Dobbins et al., 2009; Cvitanovic et al., 2016). Thus, while knowledge brokering roles present a number of challenges, when operating efficiently, knowledge brokers are believed to have the ability to facilitate organizational change by (I) removing barriers to evidence-based decision-making, (2) promoting a culture that values the use of the best available science in policy and practice and (3) influencing science so that it is appropriate to stakeholder needs (Meyer, 20I0).

Despite growing rhetoric regarding the potential benefits associated with knowledge brokers in relation to environmental resource management, to date the evidence in support of such claims is mostly anecdotal, and derived primarily from other sectors such as the medical and education sectors (see review by Cvitanovic et al., 20I5b). Indeed, to our knowledge no study to date has quantitatively demonstrated the value of using knowledge brokers to connect scientists and decision-makers in relation to environmental challenges, nor comprehensively documented the ways in which knowledge brokers can add value to knowledge exchange processes. This is, in part, due to the lack of established methods to evaluate the effectiveness and efficiency of knowledge brokers, or the types of activity they undertake (Fazey et al., 20I3; Adelle, 2015).

The overarching objective of this paper is to help address this gap by testing the utility of social network analysis (SNA) to monitor and evaluate the effectiveness of knowledge brokers at connecting scientists and decisionmakers. Specifically, using a case-study approach, we undertake longitudinal SNA to evaluate the extent to which a knowledge broker can develop relationships and networks with and between producers and users of knowledge to support the uptake and impact of scientific outputs to inform decision-making processes. SNA is considered 
a useful approach because of its potential to identify the position of individuals within a network and give meaning to the underlying structure and relationships in the network (Bodin and Crona, 20o9; Jedd and Bixler, 2015). Network structure and position play crucial roles in the circulation of knowledge within the system (see, e.g., Dowd et al., 20I4; Cunningham et al., 2015). Accordingly, longitudinal SNA allows researchers to monitor how network structures change over time, which when applied to a knowledge broker's network can provide empirical evidence for the extent to which the knowledge broker has been successful at connecting scientists and decision-making and thus provide opportunity for improved knowledge exchange (Toikka, 20I0).

While this study is primarily concerned with testing the utility of SNA to monitor and assess the effectiveness of knowledge brokers, as a secondary aim this paper also begins to explore the extent to which knowledge brokers can facilitate knowledge exchange among scientists and decision-makers. This is achieved via a qualitative survey of scientists employed within the same agency as the knowledge broker to elucidate whether they believed that working with a knowledge broker did in fact lead to improved knowledge exchange outcomes. It is important to note, however, that due to resource limitations we were unable to also interview decision-makers outside this same agency to elucidate their perceptions as to whether the knowledge broker did in fact have a positive impact on knowledge exchange processes. Thus, in presenting this data we acknowledge that the inferences as to the impact of the knowledge broker are somewhat limited, and further research in this regard will be needed.

\section{Method}

To address the aims of this study we focus on a knowledge broker employed by the Climate Adaptation Flagship at the Commonwealth Scientific and Industrial Research Organisation (CSIRO), Australia's largest research organization, as a case study. We used an ego-centric cognitive social structure approach, whereby the network is first bound by the knowledge broker's interpretation of the network and second verified by actors within the network (Hawe et al., 2004). Such approaches have previously been used successfully within the medical sector to evaluate the temporal development of collaborative relationships, and the influence of such relationships on the uptake of new biomedical discoveries into clinical practice (Long et al., 20I6).

In this study there are four data sets, two quantitative and two qualitative. The quantitative data sets include the knowledge broker's ego-centric networks over time, and the ego networks of participants. The qualitative data sets included the knowledge broker's cognitive perceptions of the whole network, as well as a qualitative survey of the knowledge broker's effectiveness completed by network members from CSIRO. The method of data collection for the four data sets will be described in the following section.

\section{Social Network Analysis}

An ego-centric analysis describes an individual's network from the point of view of the individual (ego). This longitudinal SNA of a knowledge broker was taken over a one-year period from the commencement of the role in $20 \mathrm{O} 2$. Network progress (i.e. new connections to the broker) was recorded in four different time periods (3 months, 6 months, 9 months and I2 months). Specifically, the knowledge broker recorded the name and role of each individual with whom they interacted during this period. At the end of the I2-month period a total of I92 individuals were part of the knowledge broker's network.

Aside from the knowledge broker's identification of persons who became part of his ego network for each 3-month interval over the I2-month period, the knowledge broker also identified connections between all other nodes, reflecting how he perceived the whole network to be structured and creating a cognitive social network. A subset of the 192 individuals who were part of the knowledge broker's ego network and cognitive social structure survey were invited to also identify their connections to others in the network, in order to check and validate the knowledge broker's perceptions of the connections between other contacts in the network. As these contacts were both internal and external to the home organization of the knowledge broker, in this instance purposive sampling was employed and internal contacts were invited to participate within this survey. From this sample, a total of 
I6\% (3I) of the network responded to this survey; however, only 29 of these responses were usable due to missing data. As the response rate was less than 50\%, a whole network approach was not possible. Instead, a symmetric matrix of 192 rows and I92 columns with every member was developed, including the responses from 29 participants and the knowledge broker, with the remainder for the rows having nil values. This matrix was then compared with the knowledge broker's cognitive social network for analysis (Wasserman and Faust, I994).

It is important to note that the network in each time period changed, as it was a dynamic network with members coming and going, hence it was not possible to quantitatively compare these networks directly. This is because social networks of different persons inherently have different ties. Therefore, in order to explore similarities between networks over time, all members included in the ego network at the I2-month time point were included in each time period as inactive nodes if they were not already present in the network.

The quantitative network information was supplemented with qualitative information about the "quality or strength' of each of the interactions at the end of every three-month period. The knowledge broker ranked the interactions between himself and individuals in the network as being either weak, moderate or strong, and recorded any perceived change. In doing so, this ranking does not follow the definition of weak ties provided by Granovetter (I973), but instead is a qualitative judgement from the knowledge broker regarding how strong he felt his relationship was with each node of the network.

Using the qualitative data on the knowledge broker's perception of the strength of the interactions, we were also able to conduct a cognitive social network analysis. A cognitive social network analysis is the study of how other actors perceive the dynamics in their networks (in this case the strength of the interaction) and act accordingly (Krackhardt, I987; Houghton et al., 2015). This approach allowed us to test the accuracy of the knowledge broker's own perception of the strength of the interactions (Borgatti et al., 2013) and how others in their network perceived this interaction strength. Krackhardt (I987) found that individuals who were able to more accurately perceive their network were able to have more directive influence than others. In this study we are also interested in how the knowledge broker's perception of interaction strength is reflected in a quantitative analysis of bridging and bonding ties in the network.

In general, the collection of cognitive social network data is difficult to obtain. In cases where the bounded network is reasonably large, the task may be virtually impossible, but relatively small networks $(N<50)$ have provided useful insights in many studies of social and organizational phenomena (e.g. Noel et al., I979; Kilduff and Tsai, 2003). Therefore, this study provided us with the opportunity to have the knowledge broker reflect upon the ties between actors, on a consistent basis over time, providing us with the rich data needed to understand his perceptions of all ties.

To undertake the SNA within this study we utilize UCINET@, a program specifically developed by Analytics Technologies for analysing social networks. We used Cytoscape to draw the network figures due to the flexibility in the graphics component. Using UCINET we calculated values for network cohesion, which included, but were not limited to, average degree, average distance, closure, components (number of cliques), density and fragmentation (Bodin and Prell, 20II; Borgatti and Halgin, 20II). These measures were included as they provide an understanding of how well connected different nodes/actors within a social network are to one another (Table I), with a range of evidence showing that cohesion is a key factor underpinning knowledge flow and exchange among the various nodes/actors within that networks (e.g. Turner et al., 20I4; Cunningham et al., 2015). Thus, measures of cohesion are most relevant to the aims of this study.

\section{Ethical Considerations of Social Network Analysis}

In utilizing this approach it is important to note that our research design identified and addressed the ethical challenges facing such a study due to the ethnographical nature of the data, to ensure that the identity and privacy of study participants was protected (Bryman, 20I2). To do this we utilized the principles highlighted by Borgatti and Molina (2003), specifically related to the collection, analysis and storage of the data. As such, the research team had clearly structured timelines on how and when data would be attained; alerted participants to the ethnographical nature of the study as well as providing information on how the data would be stored, used and reported; had stated protocols for data handling and storage; allocated analysis to a team member not directly reporting to the research 


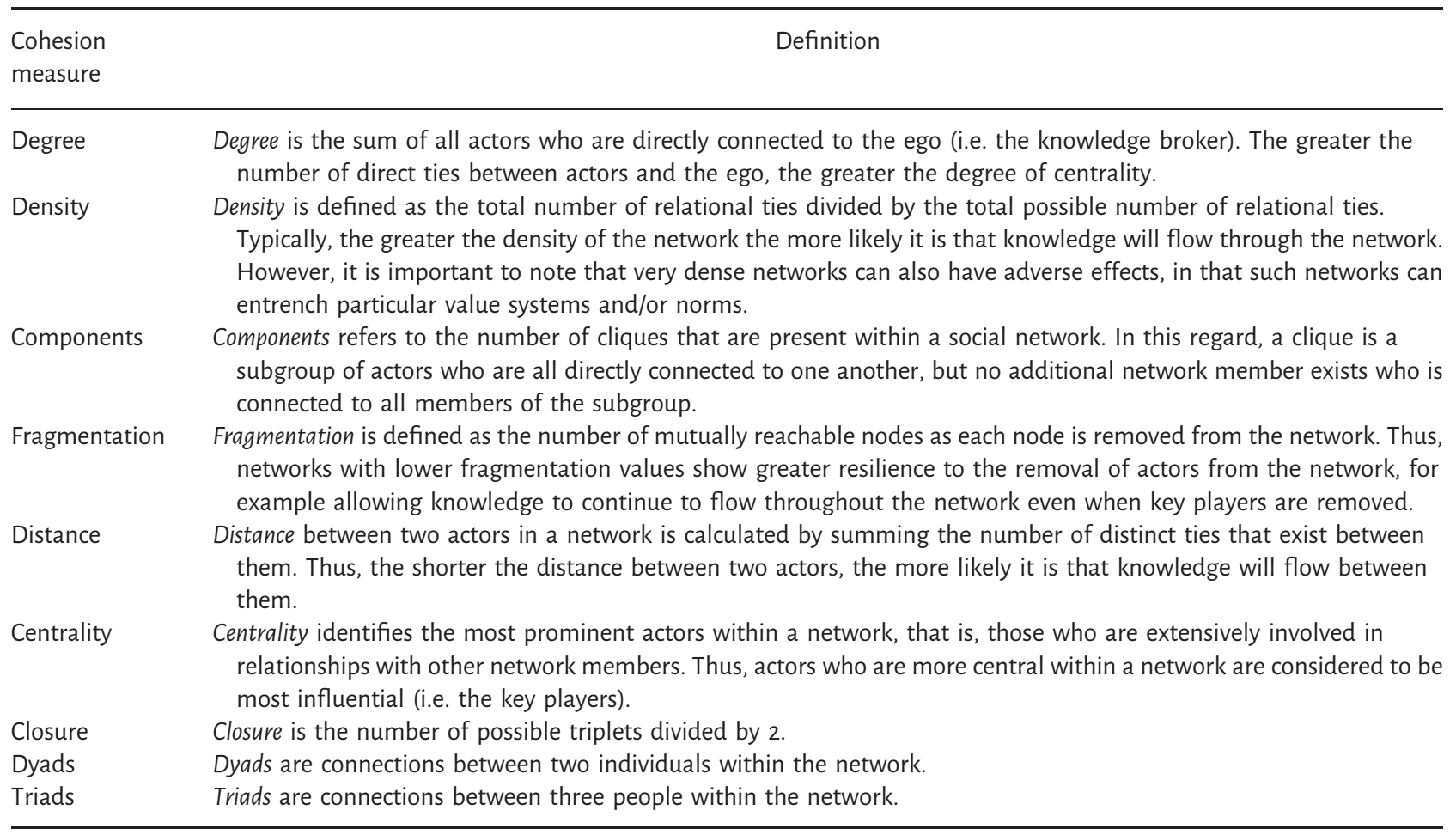

Table 1. Definition of cohesion measures used in SNA (based on Hawe et al., 2004)

subject and obtained ethical clearance from an independent committee in order to ensure our research was in line with Australian ethical practice.

\section{Qualitative Survey of CSIRO Scientists}

Further to the SNA, to better understand the extent to which a knowledge broker can facilitate knowledge exchange among scientists and decision-makers we also developed an online qualitative survey, which was distributed at the I2-month point to internal CSIRO research scientists who were part of the knowledge broker's network. As outlined earlier, limited resources prevented us from being able to also implement this survey with decision-makers within the knowledge brokers network. The survey was comprised of three questions:

I. Do you believe that having a knowledge broker employed in the Climate Adaptation Flagship has added benefit to the Flagship, and why/why not?

2. Do you believe that having a knowledge broker employed by the Climate Adaptation Flagship has benefited you personally, and why/why not?

3. Based on your experience working with the Climate Adaptation Flagship knowledge broker, do you believe that knowledge brokers can improve the transfer and uptake of scientific information to end-users, and why/why not?

For each of the questions the participants were required to answer either 'yes', 'no' or 'I'm not sure', and were also provided with a text box to provide an explanation for their response. All responses were transferred into an Excel spreadsheet, coded against the key themes of the questions outlined above and analysed (Bryman, 20I2). In total, 29 internal CSIRO research scientists who were also members of the knowledge broker's network completed this survey. 


\section{Results}

\section{Ego-Network Analysis}

Across the I2-month period, which formed the basis of this study, the knowledge broker's network grew to include I9 2 actors. As may be expected, this growth was fastest at the commencement of the position, with the network containing 88 entities after three months, I40 after six months, I8I after nine months and I92 after I2 months of operation. These individuals spanned over 30 national and international organizations, including commonwealth and state government agencies, natural resource management groups, universities and research institutions, community groups and the private sector. Furthermore, only $46 \%$ of individuals were internal to the knowledge broker's home institution, demonstrating the dominant end-user focus of these roles.

The SNA provides important insights (see Table 2) into the development of this network over time, demonstrating that over the I2-month period the network became more cohesive and dense. Specifically, the density of the knowledge broker's network increased from 0.05 after three months in the position to 0.IO 8 after I2 months. This means that the potential number of connections in the network increased by $5 \%$ (if every person in the network was connected to every other person in the network, the density would be equal to one).

Similarly, the SNA showed that the individual network components' value decreased from Io6 after three months in the role to 5 after I2 months in the role. That is, over time the knowledge broker's network became more cohesive, as actors within the networks formed new ties with others in the network. Furthermore, the average distance between two people in the network increased over time from 1.926 to 2.308 (which is a relatively small increase nevertheless), most likely as a consequence of the increase in the size of the network (i.e., the number of nodes increases from 88 to I92 - Table 2). This means that, as well as the network being larger and more cohesive, most people also gained new connections with other people in the network aside from the knowledge broker.

Based on the ego network, strength of ties increased across the I2-month period as the knowledge broker's relationships with internal and external stakeholders grew (Figure I). Strength of tie is a key element for ease of cooperation and work efficiency when collaborating both intra- and inter-organizationally, and as such this finding illustrates the knowledge broker's ability to connect people within his network to facilitate the two-way exchange of knowledge. Unsurprisingly, this also translates to each individual, or node, within the knowledge broker's network increasing their average number of connections over time from IO.I connections after three months to 20.5 after I2 months.

The change in the quality of the connections was assessed by the knowledge broker himself, over the i2-month period (shown graphically in Figure 2). Approximately i2 \% of connections started off as strong and remained so for the duration of the study. Approximately $58 \%$ of connections were weak at the start of the study and remained so for the i2-month duration, while $36 \%$ of connections increased in strength from either weak to moderate or strong, or from moderate to strong, over the I2-month period.

\section{Cognitive Social Network Analysis}

We adopted the partial-consensus method in determining the 'true' network in which to compare the perceptions of the knowledge broker. This approach takes into account the perceptions of not just two nodes but almost all those in

\begin{tabular}{|c|c|c|c|c|}
\hline Number of individuals (nodes) & 88 & 140 & 181 & 192 \\
\hline Density & 0.053 & 0.078 & 0.1 & 0.108 \\
\hline Components & 106 & 55 & 16 & 5 \\
\hline Fragmentation & 0.796 & 0.483 & 0.146 & 0.036 \\
\hline
\end{tabular}

Table 2. Cohesion measures for the knowledge broker ego network compared in four time periods 


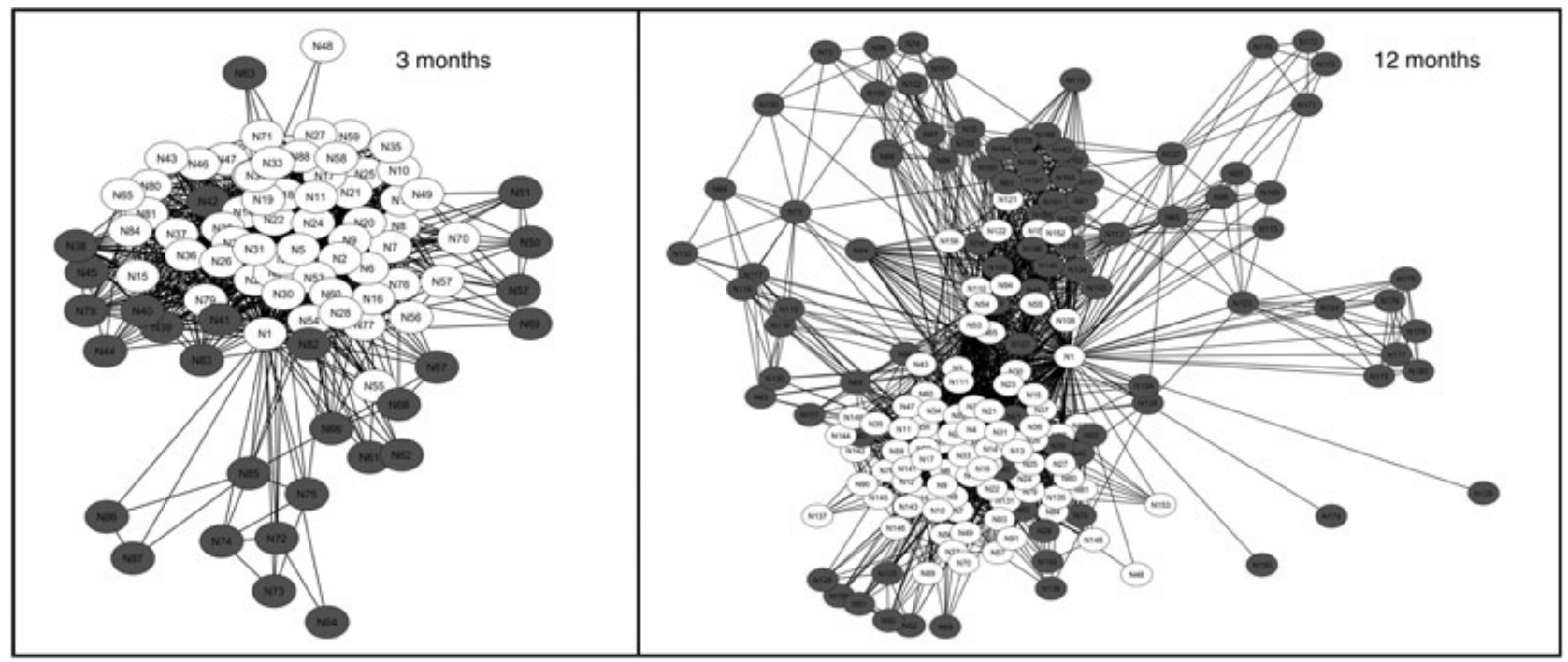

Figure 1. Knowledge broker ego network comparing the 3-month and 12-month time periods. N1 indicates knowledge broker. White nodes indicate CSIRO employees while grey nodes indicate external stakeholders

the network. Due to not achieving full consensus data, with only 29 ( $15 \%$ ) of the 192 nodes surveyed, we can only use this subsample to represent consensus.

From a centrality perspective (Table 3), the knowledge broker perceived himself to be highly connected, with an indegree centrality measure much larger than what was reflected by the partial-consensus network (KB, 0.495; PC, 0.099). The outdegree centrality figure was more closely aligned, demonstrating that the network members reported similar, although greater, numbers of outgoing ties (KB, 0.52I; PC, 0.956). There is a considerable difference between the number of ties of each node reported by the knowledge broker compared to the rest of the network (average degree $\mathrm{KB}, 20$; $\mathrm{PC}$, 9), which is likely driven by the low response rate.

In regards to the perceptions of connectedness (Table 3), the knowledge broker self-assessed as being connected to all nodes (KB, I) (Figure 2), which is not surprising since this is an ego network. However, the true network does not suggest the knowledge broker to be as highly connected as he perceives himself to be (PC, O.I5I). This result reflects the similar findings above, related to centrality. In addition, the knowledge broker does not recognize any fragmentation (KB, ०.036), compared with the minor recognition from the partial consensus (PC, o.849), and perceives cohesion to be higher (KB, II.7\%) than the true network (PC, 4.9\%).

Using reciprocity (KB, 0.690; PC, O.I40), transitivity (KB, 0.50I; PC, 0.569) and closure (KB, 0.444; PC, 0.357) as measures of the network's structure, observations can be made regarding the consistency of the triad value and the increasing value for the dyads (Table 3). For example, a change in the value of the triads is of interest in this study, as they indicate where the knowledge broker facilitated closure between two other individuals within his network. Results show that the greatest difference is reflected at the dyad level, but this, once again, could be reflective of the low response rate of all network members or because participants were not in a position to assess the knowledge broker's relationship with other individuals in the network. At the triad level there is greater agreement on the relationships between nodes. This implies that the knowledge broker has a good understanding of the connections between clusters of people within the network and how they interact.

Overall, this analysis shows that the knowledge broker perceived himself to be highly central and well connected within a moderately dense network in which he played a significant bridging and bonding role between known groups of people. The true network reflects that the knowledge broker is highly perceptive when it comes to knowing 'who is connected to whom', which serves him well when working in a bridging capacity. This is reflected in the average distance result, which show strong agreement between the knowledge broker $(\mathrm{KB}, 2.308)$ and the true network (PC, I.679). 


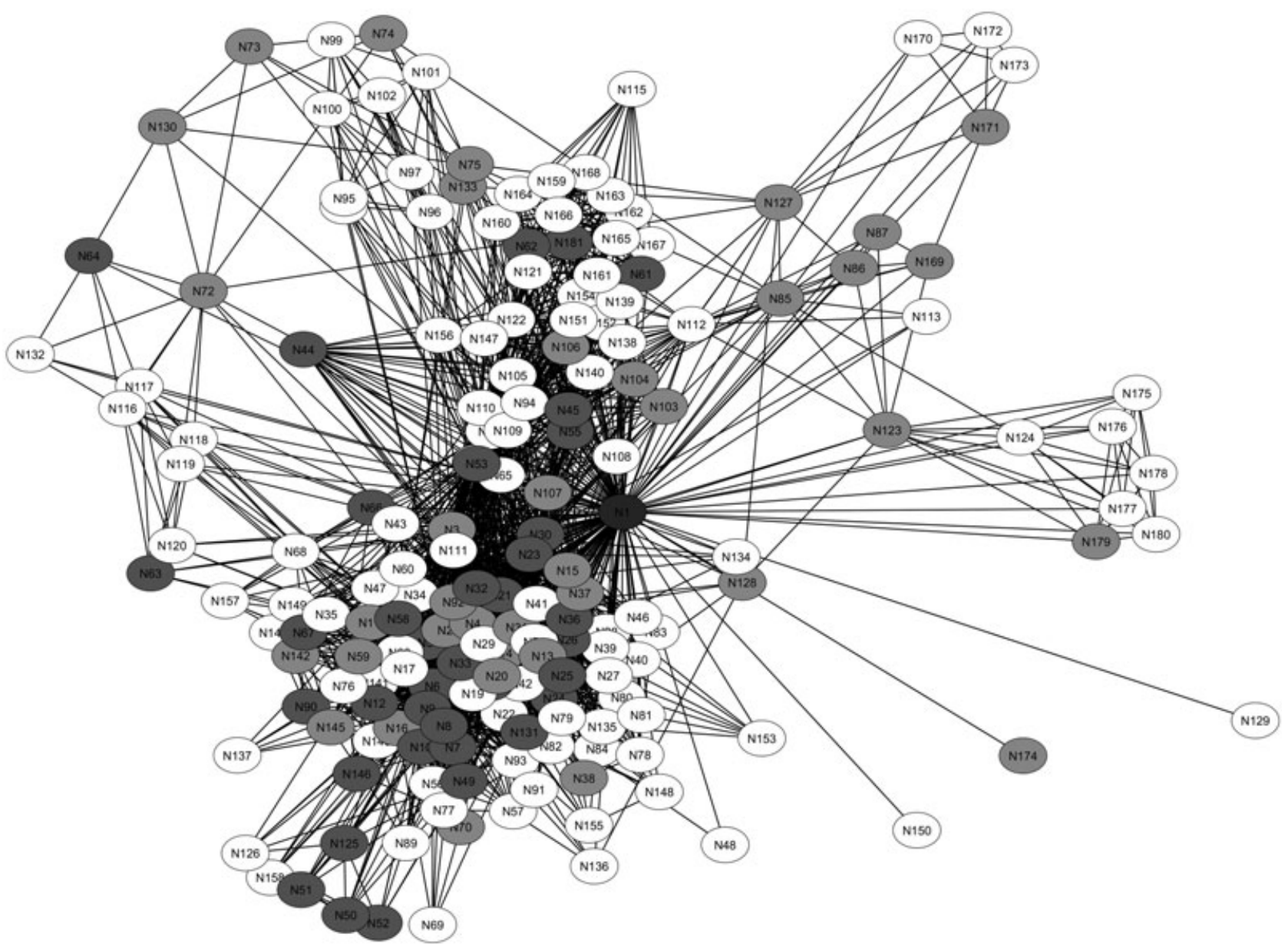

Figure 2. Change in the strength of relationship between nodes within the network as assessed by the knowledge broker. Dark grey indicates that there is an increase in the strength of relationship over time, whereas light grey indicates that the relationship is moderate or strong but does not change over time. White nodes represent a weak relationship that does not change over time. The knowledge broker is shown in black

\section{Perceptions of the Effectiveness of a Knowledge Broker}

When asked 'Do you believe that having a knowledge broker employed in the Climate Adaptation Flagship has added benefit to the Flagship?', $73 \%$ of participants answered 'yes' ( $n=2 \mathrm{I}$ ), with $24 \%$ and $3 \%$ answering 'I'm not sure' and 'no' respectively. Of those that voted 'yes', i2 individuals stated that the primary reason for their response was the ability of the knowledge broker to build better connections with and among key stakeholders, which led to the improved diffusion of knowledge and better science outcomes. Furthermore, several participants also stated that, via the knowledge broker, they had developed a more comprehensive understanding of the research needs of various stakeholders, leading to improved and targeted delivery of new information. In turn, two participants also noted that the improved understanding of stakeholder needs led to the Flagship becoming more competitive when applying for research funding.

Similarly, when asked 'Do you believe that having a knowledge broker employed by the Climate Adaptation Flagship has benefited you personally?', 62\% (n= I8) of participants stated 'yes', with $21 \%$ and I7\% answering 'I'm not sure' and 'no' respectively. Most participants identified the ability of the knowledge broker to help their individual networks to develop as the primary reason for their response. Furthermore, several participants also described how the knowledge broker was able to provide guidance and training on stakeholder engagement to help improve the 


\begin{tabular}{lcc}
\hline Network measures & Knowledge broker (KB) & Partial consensus (PC; N = 29 respondents) \\
\hline How central are the nodes? & & 0.099 \\
In-degree centrality & 0.521 & 0.956 \\
Out-degree centrality & 20.482 & 9.271 \\
Average degree & & 0.151 \\
How connected is the network? & 0.964 & 0.849 \\
Connectedness & 0.036 & 0.049 \\
Fragmentation & 0.108 & 1.679 \\
Density & 2.308 & 0.467 \\
Average distance & 0.752 & 0.140 \\
Standard deviation distance & & 0.569 \\
What is the structure of the network's ties? & 0.690 & 0.357 \\
Dyad reciprocity & 0.501 & 0.444 \\
Triad transitivity & & \\
Closure & & \\
\hline
\end{tabular}

Table 3. Comparison of perceptions of the network

individual ability of researchers to engage more effectively (e.g. workshop strategies, social media training etc.). For example, as stated by one participant, '(the knowledge broker) has introduced me to new networks, facilitated networks for me and discussed (options) for new networks. He has helped with communication weaknesses and stimulated discussion about knowledge transfer'. Similarly, another participant stated '(the knowledge broker) has shaped the way that I communicate with stakeholders as well as providing me with insight into the inner workings of other organizations and their political situations'. Building on the above, when asked 'Based on your experience working with the Climate Adaptation Flagship knowledge broker, do you believe that knowledge brokers can improve the transfer and uptake of scientific information to end-users?', $69 \%(n=20)$ of participants stated 'yes', with $28 \%$ and $3 \%$ answering 'I'm not sure' and 'no' respectively.

\section{Discussion}

\section{Key Findings and Implications}

In response to the growing urgency and complexity of environmental problems, numerous authors have advocated the use of knowledge brokers to improve knowledge exchange between scientists and decision-makers, thus enhancing the likelihood of evidence-based decision-making (e.g. Cvitanovic et al., 20I4b; Hering, 20I5; Lacey et al., 20I5). Despite this growing rhetoric, however, very little empirical evidence in support of these roles exists, largely due to the lack of established methods to evaluate the effectiveness and efficiency of knowledge brokers, or the types of activities they undertake (but see Fazey et al., 20I4). The present study addresses this gap by testing the utility of longitudinal social network analysis to evaluate the extent to which a knowledge broker developed relationships with and between producers and users of climate knowledge to enhance the uptake and impact of scientific outputs to inform decision-making processes. In doing so, we not only demonstrate the value of this method for evaluating and monitoring knowledge brokers, but also provide empirical support for the use of knowledge brokers.

In the broadest sense, knowledge brokerage has been defined as the full suite of activities required to link decision-makers with researchers, facilitating their interaction so that they are better able to understand each other's goals and professional cultures, influence each other's work, forge new partnerships and promote evidence-based decision-making (Lomas, 2007). Knowledge brokers are agents who support this agenda by facilitating interaction and engagement among researchers and end-users to enhance knowledge exchange, enable the use of scientific knowledge in decision-making processes and strengthen research impact (reviewed by Knight and Lightowler, 20I3). Underpinning this is the extent to which knowledge brokers can build and sustain productive working 
relationships with a range of both internal (researchers) and external (end-users) stakeholders. In the present study, the knowledge broker successfully developed an extensive stakeholder network of almost 200 individuals spanning 30 organizations within only I2 months. More importantly, the results of the SNA found that across the I2-month period this network increased in density and became more cohesive, both thought to be key elements underpinning successful knowledge exchange in the pursuit of evidence-based decision-making (Crona and Bodin, 2006).

While on their own the results of the SNA to do not demonstrate an increased uptake of scientific evidence into decision-making processes, they do offer promise for the enhanced governance of natural resources. For example, in recent times an expanding body of literature has identified the existence of social networks as a common and important factor in cases where different stakeholders have come together to deal effectively with natural resource problems (Bodin and Crona, 2009; Sandström et al., 20I4). Indeed, it has been shown in some cases that social networks can be more important than the existence of formal institutions for the effective management of environmental assets (Scholz and Wang, 2006). This is because strong social networks have been shown to improve collaborative governance processes by facilitating the generation, acquisition and diffusion of different types of knowledge and information in relation to the ecosystem of concern (Crona and Bodin, 2006). This is supported by the results of this study, with the majority of respondents of the qualitative survey stating that the establishment of social networks by the knowledge broker led to improved knowledge exchange and better science outcomes. As a result, it is inferred that through the formation of this network the knowledge broker has improved the impact of scientific outputs and contributed towards improved resource governance.

Further to the establishment of new networks, researchers who took part in the qualitative survey also identified that the knowledge broker was able to have a positive impact by improving their understanding of the information needs of different stakeholders and their effectiveness in engaging with them. This included helping researchers to understand the operating environments within decision-making agencies, in turn leading to the implementation of improved and more targeted engagement and knowledge exchange processes. This is considered particularly important in situations where decisions are made within organizations where decision-making processes are constrained by resources, regulations or perceptions (Jacobs et al., 2005; Jantarasami et al., 2010). Furthermore, these findings are significant in light of evidence that a key barrier undermining knowledge exchange between scientists and decision-makers is a lack of awareness among scientists regarding the information needs of decision-makers (Cvitanovic et al., 20I5a; Dunn et al., 20I5), which is often attributed to decision-makers not clearly or effectively articulating knowledge needs (Roux et al., 2006). Thus these results provide evidence that knowledge brokers can help overcome cultural and institutional barriers between scientists and decisions-makers to promote two-way knowledge exchange between these groups. As a downstream impact of this, two respondents also noted that this increased awareness of research needs in combination with improved knowledge exchanged led to the increased funding success of research proposals.

Despite the benefits outlined above, knowledge brokers are not routinely implemented in the environmental and resource management sectors. This may, in part, arise from the lack of evidence in support of these roles, particularly given the significant transaction costs that can be associated with their implementation (see, e.g., Cash et al., 2006; Buizer et al., 2010; Jacobs, 2014). This is compounded by knowledge brokers often not being recognized as core positions within research institutions or decision-making agencies, and thus when resources are limited, investment is focused towards research activities as opposed to those associated with stakeholder engagement and knowledge brokering (Boschetti et al., 20I6). From the results of this study, however, we suggest that when implemented efficiently knowledge brokers can provide an effective return on investment in numerous ways (Hering, 20I5).

Drawing on the knowledge broker literature from other sectors (primarily the medical and education sectors), key insights regarding the factors contributing to the effective implementation of knowledge brokers can be gleaned. In particular, given the significant time needed to develop an expansive stakeholder network built on mutual trust (Meadow et al., 20I6), and then connect actors within this network to facilitate knowledge exchange (Jacobs et al., 20I0), knowledge brokers should be implemented as part of a long-term organizational strategy rather than as part of a specific short-term project (Dobbins et al., 2009). Doing so allows for the full development of the relationship among actors within the network, which will strengthen over time, thus improving the likely uptake of scientific knowledge into decision-making processes. This, however, is seldom the case, with evidence from the education sector showing that knowledge broker roles are typically dependent upon project-based funding. Accordingly, 
institutional innovation among research organizations is required to better support the implementation of knowledge brokers and other forms of stakeholder engagement as part of a long-term funded engagement strategy (Reed, 2008; Lacey et al., 20I5). This must also include clear career pathways to support their development (Knight and Lightowler, 2013).

\section{Study Limitations and Future Research Needs}

While the results of this study support the use of SNA to monitor and assess the impact of knowledge brokers, there are several limitations to our approach that should be corrected in future studies to build on the data presented here. First, while our results do suggest that knowledge brokers can enhance knowledge exchange among scientists and decision-makers in the environmental sector, it is important to note that these inferences are drawn from a single case study (i.e., $n=\mathrm{I}$ ). As such, care must be taken not to overinterpret these findings, and we suggest that future research could apply the methods described in this study more broadly to a range of knowledge brokerage settings to develop a systematic and more grounded evidence base regarding the potential benefits of using knowledge brokers.

Building on the above, and as illustrated via the cognitive network analysis, the ability to draw generalized conclusions in cases where low response rates are received from the total number of network members is limited. Therefore, future studies utilizing this methodology should seek to achieve a full consensus network to ensure that more accurate conclusions regarding the impact of the knowledge broker can be drawn. Achieving a full consensus, however, is more resource intensive and should be planned for at the onset of future research.

Furthermore, while the results of the SNA do demonstrate the extent to which knowledge brokers can connect producers and users of environmental science, they do not demonstrate an increased uptake of scientific evidence into decision-making processes. While this evidence of uptake may have been documented by undertaking qualitative interviews with the decision-makers within the knowledge brokers network, resource limitations prevented this from occurring in this case. As such, future studies seeking to evaluate the effectiveness of knowledge brokers in linking science to action should ensure that steps are taken to elucidate the extent to which the connections developed by the knowledge broker led to increased knowledge exchange and enhanced capacity for evidence-based decision-making.

Finally, future research is also needed to identify the core capacities that are needed to ensure the success of knowledge brokers (Cvitanovic et al., 20I6). In this regard, 'capacities' is defined as both the capabilities to act, and the competences required to do so (Franks, I999), and include the individual, social, political, material, technical, practical and financial elements required to support knowledge exchange and evidenced-based decision-making (Eade, 2007). Developing a comprehensive understanding of the capacities required to underpin successful knowledge brokering could be achieved via more in-depth qualitative evaluations of knowledge brokers and the activities they perform, and should be the focus of future studies.

\section{Conclusions}

In the pursuit of evidence-based decision-making in response to modern day environmental challenges, a growing body of literature advocates for the use of knowledge brokers as one mechanism to improve knowledge exchange among scientists and decision-makers. Despite this growing rhetoric, however, very little empirical evidence in support of these roles exists, largely due to the lack of established methods to evaluate the effectiveness and efficiency of knowledge brokers, or the types of activities they undertake. In this study we make progress towards addressing this gap by testing the utility of social network analysis to monitor and evaluate the effectiveness of knowledge brokers in connecting scientists and decision-makers. In doing so, we demonstrate the potential value of this method for evaluating and monitoring knowledge brokers, but highlight a range of limitations in our approach that should be addressed in future studies.

The findings in the present study provide initial empirical support for the use of knowledge brokers in the environmental sector. Specifically, we demonstrate that when implemented efficiently knowledge brokers have the ability to develop relationships and networks with, among and between producers and users of knowledge to facilitate 
the exchange of knowledge throughout this network and build capacity for evidence-based decision-making. We also show that knowledge brokers can have a range of positive impacts on research organizations, for example by helping researchers understand the operating environments within decision-making agencies, in turn leading to the implementation of improved and more targeted engagement and knowledge exchange processes. Thus, when implemented efficiently, our results suggest that knowledge brokers have the ability to facilitate organizational change by (I) partly removing barriers to evidence-based decision-making, (2) promoting a culture that values the use of the best available science in policy and practice and (3) influencing science so that it is appropriate to stakeholder needs.

\section{Acknowledgements}

We thank C. James, S. Crimp and A. Hobday for useful discussions that contributed to the design of this study. We also thank all participants who took part in the surveys. Financial support was provided by the now-defunct CSIRO Climate Adaptation Flagship. Finally, we thank the two anonymous reviewers whose comments helped improve the manuscript.

\section{References}

Addison PFE, Flander LB, Cook CN. 2015. Are we missing the boat? Current uses of long-term biological monitoring data in the evaluation and management of marine protected areas. Journal of Environmental Management I49: I48-I56.

Adelle C. 20I5. Contextualising the tool development process through a knowledge brokering approach: the case of climate change adaptation and agriculture. Environmental Science and Policy 51: 316-324.

Armitage D, Marschke M, Plummer R. 2008. Adaptive co-management and the paradox of learning. Global Environmental Change I8: 86-98.

Berkes F, Colding J, Folke F (eds). 2003. Navigating Social-Ecological Systems: Building Resilience for Complexity and Change. Cambridge University Press: Cambridge.

Berrang-Ford L, Ford JD, Paterson J. 20II. Are we adapting to climate change? Global Environmental Change 2r: 25-33.

Bodin O, Crona BI. 2009. The role of social networks in natural resource governance: what relational patterns make a difference? Global Environmental Change 19: 366-374.

Bodin O, Prell C. 20II. Social Networks and Natural Resource Management: Uncovering the Social Fabric of Environmental Governance. Cambridge University Press: Cambridge.

Borgatti SP, Halgin DS. 20II. On network theory. Organization Science 22(5): II68-II8I.

Borgatti SP, Molina JL. 2003. Ethical and strategic issues in organizational social network analysis. Journal of Applied Behavioural Sciences 39(3): 337-349.

Borgatti SP, Everett MG, Johnson JC. 20I3. Analyzing Social Networks. SAGE: London.

Bornbaun CC, Kornas K, Peirson L, Rosella LC. 20I5. Exploring the function and effectiveness of knowledge brokers as facilitators of knowledge translation in health-related settings: a systematic review and thematic analysis. Implementation Science Io: I62.

Boschetti F, Cvitanovic C, Fleming A, Fulton E. 20I6. A call for empirically based guidelines for building trust among stakeholders in environmental sustainability projects. Sustainability Science II: 855 .

Bryman A. 2012. Social Research Methods. Oxford University Press: Oxford.

Buizer J, Jacobs K, Cash D. 20I0. Making short-term climate forecasts useful: linking science and action. Proceedings of the National Academy of Sciences. DOI:Io.1073/pnas.0900518107.

Cash D, Buizer J. 2005. Knowledge-Action Systems for Seasonal to Interannual Climate Forecasting: Summary of a Workshop. National Academies Press: Washington, DC.

Cash DW, Clark WC, Alcock F, Dickson NM, Eckley N, Guston DH, Jager J, Mitchell RB. 2003. Knowledge systems for sustainable development. Proceedings of the National Academy of Sciences Ioo: 8086-809I.

Cash DW, Borck JC, Patt AG. 2006. Countering the loading dock approach to linking science and decision making: comparative analysis of El Nino/Southern Oscillation (ENSO) forecasting systems. Science, Technology and Human Values 3r: 465-494.

Cornell S, Berkhout F, Tuinstra W, Tàbara JD, Jäger J, Chabay I, de Wit B, Langlais R, Mills D, Moll P, Otto IM, Petersen A, Pohl C, van Kerkhoff L. 20I3. Opening up knowledge systems for better responses to global environmental change. Environmental Science and Policy 28: 60-70.

Crona BI, Bodin O. 2006. What you know is who you know? Communication patterns among resources extractors as a prerequisite for comanagement. Ecology and Society II: 7.

Cunningham R, Cvitanovic C, Measham T, Jacobs B, Dowd AM, Harman B. 20I5. Engaging communities in climate adaptation: the potential of social networks. Climate Policy i6: 894-908.

Cvitanovic C, Wilson SK, Fulton CJ, Almany GR, Anderson P, Babcock RC, Ban NC, Beedon R, Beger M, Cinner J, Dobbs K, Evans LS, Farnham A, Friedman K, Gale K, Gladstone W, Grafton Q, Graham NAJ, Gudge S, Harrison P, Holmes TH, Johnstone N, Jones GP, Jordan A, 
Kendrick A, Klein CJ, Little LR, Malcolm H, Morris D, Possingham HP, Prescott J, Pressey RL, Skilleter GA, Simpson C, Waples K, Wilson D, Williamson DH. 20I3. Critical research needs for managing coral reef marine protected areas: perspectives of academics and managers. Journal of Environmental Management II4: 84-9I.

Cvitanovic C, Fulton CJ, Wilson SK, van Kerkhoff L, Cripps IL, Muthiga N. 20I4a. Utility of primary scientific literature to environmental managers: an international case study on coral-dominated marine protected areas. Ocean and Coastal Management I02: 72-78.

Cvitanovic C, Marshall NA, Wilson SK, Dobbs K, Hobday AJ. 20I4b. Perceptions of Australian marine protected area managers regarding the role, importance, and achievability of adaptation for managing the risks of climate change. Ecology and Society I9(4): 33.

Cvitanovic C, Hobday AJ, van Kerkhoff L, Marshall NA. 20I5a. Overcoming barriers to knowledge exchange for adaptive resource management; the perspectives of Australian marine scientists. Marine Policy 52: 38-44.

Cvitanovic C, Hobday AJ, van Kerkhoff L, Wilson SK, Dobbs K, Marshall NA. 2oI5b. Improving knowledge exchange among scientist and decision-makers to facilitate the adaptive governance of marine resources: a review of knowledge and research needs. Ocean and Coastal Management II2: 25-35.

Cvitanovic C, McDonald J, Hobday AJ. 20I6. From science to action: principles for undertaking environmental research that enables knowledge exchange and evidence-based decision-making. Journal of Environmental Management I83: 864-874.

Dobbins M, Robeson P, Ciliska D, Hanna S, Cameron R, O’Mara L, DeCorby K, Mercer S. 2009. A description of a knowledge broker role implemented as part of a randomized controlled trial evaluating three knowledge translation strategies. Implementation Science 4: 23.

Dowd AM, Marshall N, Fleming A, Jakku E, Gaillard E, Howden M. 20I4. The role of networks in transforming Australian agriculture. Nature Climate Change 4: $55^{8-563 .}$

Dunn M, Lindesay J, Howden M. 20I5. Spatial and temporal scales of future climate information for climate change adaptation in viticulture: a case study of user needs in the Australian wine-grape sector. Australian Journal of Grape and Wine Research 221: 226-239.

Eade D. 2007. Capacity building: who builds whose capacity? Development in Practice I7: 630-639.

Fazey I, Evely AC, Reed MS, Stringer LC, Kruijsen J, White PVL, Newsham A, Jin L, Cortazzi M, Phillipson J, Blackstock K, Entwistle N, Sheate W, Armstrong F, Blackmore C, Fazey J, Ingram J, Gregson J, Lowe P, Morton S, Trevitt C. 20I3. Knowledge exchange: a review and research agenda for environmental management. Environmental Conservation 40: I9-36.

Fazey I, Bunse L, Msika J, Pinke M, Preedy K, Evely AC, Lambert E, Hastings E, Morris S, Reed MS. 20I4. Evaluating knowledge exchange in interdisciplinary and multi-stakeholder research. Global Environmental Change 25: 204-220.

Folke C, Colding J, Berkes F. 2003. Synthesis: building resilience and adaptive capacity in social-ecological systems. In Navigating SocialEcological Systems: Building Resilience for Complexity and Change, Berkes F, Colding J, Folke C (eds). Cambridge University Press: Cambridge; $352-387$.

Franks T. I999. Capacity building and institutional development: reflections on water. Public Administration and Development I9: 5I-6I.

Granovetter MS. I973. The strength of weak ties. American Journal of Sociology 78: 1360-1380.

Hawe P, Webster C, Shiell A. 2004. A glossary of terms for navigating the field of social network analysis. Journal of Epidemiology and Community Health 58: 97I-975.

Hering JG. 20I5. Do we need 'more research' or better implementation through knowledge brokering? Sustainability Science II: 363-369.

Hoppe R. 2009. Scientific advice and public policy: expert advisers' and policymakers' discourses on boundary work. Poiesis and Praxis 6: $235^{-2} 63$.

Houghton RJ, Baber C, Stanton NA, Jenkins DP, Revell K. 20I5. Combining network analysis with cognitive work analysis: insights into social organisation and cooperation analysis. Ergonomics 58: 434-449.

Jacobs K. 20I4. Lessons from the National Climate Assessment on science translation and boundary organizations. US CLIVAR Variations I2(4): I-4.

Jacobs K, Garfin G, Lenart M. 2005. More than just talk: connecting science and decision-making. Environment: Science and Policy for Sustainable Development 47: 6-2I.

Jacobs K, Lebel L, Buizer J, Addams L, Matson P, McCullough E, Garden P, Saliba G, Finan T. 2oro. Linking knowledge with action in the pursuit of sustainable water-resources management. Proceedings of the National Academy of Sciences. DOI:I0.I073/pnas.08I3I25I07.

Jantarasami LC, Lawler JJ, Thomas CW. 20IO. Institutional barriers to climate change adaptation in U.S. National Parks and Forests. Ecology and Society I5: 33.

Jedd T, Bixler RP. 2015. Accountability in networked governance: learning from a case of landscape-scale forest conservation. Environmental Policy and Governance 25: $172-\mathrm{I} 87$.

Kilduff M, Tsai W. 2003. Social Networks and Organizations. SAGE: London.

Knight C, Lightowler C. 2013. Sustaining knowledge exchange and research impact in the social sciences and humanities. Evidence and Policy 9: 3I7-334.

Krackhardt D. I987. Cognitive social structures. Social Networks 9: I09-I34.

Lacey J, Howden SM, Cvitanovic C, Dowd AM. 2015. Informed adaptation: ethical considerations for adaptation researchers and decision-makers. Global Environmental Change 32: 200-210.

Lomas J. I997. Improving research dissemination and uptake in the health sector: beyond the sound of one hand clapping. CHEPA working paper series.

Lomas J. 2007. The in-between world of knowledge brokering. British Medical Journal 334: I29-132.

Long J, Hibbert P, Braithwaite J. 20I6. Structuring successful collaboration: a longitudinal social network analysis of a translational research network. Implementation Science II: I9.

Meadow AM, Ferguson DB, Guido Z, Horangic A, Owen G, Wall T. 20I5. Moving toward the deliberate coproduction of climate science knowledge. Weather, Climate and Society 7: I79-I9I. 
Meadow AM, Guido Z, Crimmins MA, McLeod J. 20I6. From principles to action: applying the National Research Council's principles for effective decision support to the Federal Emergency Management Agency's watch office. Climate Services I: I2-23.

Meyer M. 20I0. The rise of the knowledge broker. Science Communication 32: II8-I27.

Michaels S. 2009. Matching knowledge brokering strategies to environmental policy problems and settings. Environmental Science and Policy I2: 994-IOII.

Nelson R, Howden M, Stafford-Smith M. 2008. Using adaptive governance to rethink the way science supports Australian drought policy. Environmental Science and Policy II: 588-60I.

Noel M, Tichy ML, Tushman CF. I979. Social network analysis for organizations. Academy of Management Review 4: 507-519.

Ormerod SJ, Barlow ND, Marshall ELP, Kerby G. 2002. The uptake of applied ecology. Journal of Applied Ecology 39: I-7.

Pullin AS, Knight TM, Stone DA, Charman K. 2004. Do conservation managers use scientific evidence to support their decision-making? Biological Conservation II9: 245-252.

Reed M. 2008. Stakeholder participation for environmental management: a literature review. Biological Conservation I4I: 24I7-243I.

Reed MS, Stringer LC, Fazey I, Evely AC, Kruijsen JHJ. 20I4. Five principles for the practice of knowledge exchange in environmental management. Journal of Environmental Management 146: 337-345.

Reinecke S. 20I5. Knowledge brokerage designs and practices in four European climate services: a role model for biodiversity policies? Environmental Science and Policy 54: 513-52I.

Roux DJ, Rogers KH, Biggs HC, Ashton PJ, Sergeant A. 2006. Bridging the science-management divide: moving from unidirectional knowledge transfer to knowledge interfacing and sharing. Ecology and Society II: 4.

Saarela S-R, Söderman T. 20I5. The challenge of knowledge exchange in national policy impact assessment - a case of Finnish climate policy. Environmental Science and Policy 54: 340-348.

Sandström A, Crona B, Bodin Ö. 20I4. Legitimacy in co-management: the impacts of pre-existing structures, social networks and governance strategies. Environmental Policy and Governance 24: 60-76.

Scholz JT, Wang CL. 2006. Cooptation or transformation? Local policy networks and federal regulatory enforcement. American Journal of Political Science 50: 8I-97.

Stocklmayer S. 2013. Engagement with science: model of science communication. In Communication and Engagement with Science and Technology: Issues and Dilemmas, Gilbert JK, Stocklmayer S (eds). Routledge: New York; I9-38.

Toikka A. 20Io. Exploring the composition of communication networks of governance - a case study on local environmental policy in Helsinki, Finland. Environmental Policy and Governance 20: 135-I45.

Turner RA, Polunin NVC, Stead SM. 20I4. Social networks and fishers behaviour: exploring the links between information flow and fishing success in the Northumberland lobster fishery. Ecology and Society I9(2): 38.

Wasserman S, Faust K. I994. Social Network Analysis: Methods and Applications, Vol. 8. Cambridge University Press: Cambridge. 